\title{
A relationship between protein stability and protein function
}

\author{
Brian K. Shoichet, Walter A. BaAse, Ryota Kuroki ${ }^{\dagger}$, and Brian W. Matthews $\ddagger$ \\ Institute of Molecular Biology, Howard Hughes Medical Institute, and Department of Physics, University of Oregon, Eugene, OR 97403
}

Contributed by Brian W. Matthews, October 4, 1994

\begin{abstract}
Enzymes are thought to use their ordered structures to facilitate catalysis. A corollary of this theory suggests that enzyme residues involved in function are not optimized for stability. We tested this hypothesis by mutating functionally important residues in the active site of T4 lysozyme. Six mutations at two catalytic residues, Glu-11 and Asp-20, abolished or reduced enzymatic activity but increased thermal stability by $0.7-1.7 \mathrm{kcal} \cdot \mathrm{mol}^{-1}$. Nine mutations at two substrate-binding residues, Ser-117 and Asn-132, increased

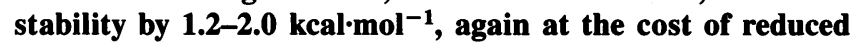
activity. X-ray crystal structures show that the substituted residues complement regions of the protein surface that are used for substrate recognition in the native enzyme. In two of these structures the enzyme undergoes a general conformational change, similar to that seen in an enzyme-product complex. These results support a relationship between stability and function for $\mathrm{T} 4$ lysozyme. Other evidence suggests that the relationship is general.
\end{abstract}

The ordered, functional structures of proteins reflect two tendencies that are often opposed. On one hand, proteins fold to minimize their free energy. On the other hand, they organize themselves to recognize a ligand or a transition state (1). Minimizing free energy leads to well-packed hydrophobic interiors and hydrophilic exteriors (2). Maximizing function leads to active-site clefts where charged and polar groups are sequestered from water $(3,4)$ and where hydrophobic patches are exposed to solvent.

The hypothesis that there is a balance between stability and function can be stated most strongly as follows: protein residues that contribute to catalysis or ligand binding are not optimal for protein stability. This "stability-function" hypothesis predicts that it usually should be possible to replace residues known to be important for function, reducing protein activity but concomitantly increasing stability of the folded protein.

Here we describe experiments that directly test the stabilityfunction hypothesis in T4 lysozyme, an enzyme well characterized for the effects of mutation on structure and stability (5). Five residues were replaced (Table 1 and Fig. 1). These included two residues implicated in chemical catalysis, Glu-11 and Asp-20 $(9,11,12)$, as well as three others thought to have a role in substrate binding, Gly-30, Ser-117, and Asp-132. We measured the thermodynamic stability and kinetic activity of the mutant lysozymes. To determine the structural consequences of the substitutions, we determined $\mathrm{x}$-ray crystal structures for several of these proteins.

\section{MATERIALS AND METHODS}

Mutagenesis and Protein Purification. Mutations were introduced into the T4 lysozyme gene borne by M13 phage derivative M13mp18 T4e by mismatched oligonucleotides using the method of Kunkel et al (13) as detailed $(6,14)$.

The publication costs of this article were defrayed in part by page charge payment. This article must therefore be hereby marked "advertisement" in accordance with 18 U.S.C. $\$ 1734$ solely to indicate this fact.
Table 1. Stability and activity of T4 lysozymes with substitutions in the substrate-binding site

\begin{tabular}{|c|c|c|c|c|}
\hline Protein & $\begin{array}{c}\Delta T_{\mathrm{m}},{ }^{\dagger} \\
{ }^{\circ} \mathrm{C}\end{array}$ & $\begin{array}{c}\Delta \Delta G_{\text {stability, }}{ }^{\dagger} \\
{\mathrm{kcal} \cdot \mathrm{mol}^{-1}}\end{array}$ & $\begin{array}{c}\Delta H\left(T_{\mathrm{m}}\right), \\
{\mathrm{kcal} \cdot \mathrm{mol}^{-1}}^{-1}\end{array}$ & $\begin{array}{l}\text { Relative } \\
\text { activity }\end{array}$ \\
\hline WT & 0 & 0 & 140 & 1 \\
\hline $\mathbf{W T}^{*}$ & 0 & 0 & 131 & 1 \\
\hline E11F & 4.3 & 1.7 & 138 & $<0.0001$ \\
\hline E11M & 4.1 & 1.6 & 134 & $<0.0001$ \\
\hline E11A & 2.6 & 1.1 & 137 & $<0.0001$ \\
\hline $\mathrm{E} 11 \mathrm{H}$ & 0.1 & 0.1 & 125 & $<0.0001$ \\
\hline $\mathrm{E} 11 \mathrm{~N}$ & -0.6 & -0.1 & 119 & $<0.0001$ \\
\hline D20N & 3.1 & 1.3 & 139 & $<0.0001$ \\
\hline D20T & 2.2 & 0.9 & 135 & $<0.0001$ \\
\hline D20S & 1.6 & 0.7 & 129 & $<0.0001$ \\
\hline D20A & -0.8 & -0.3 & 127 & 0.0005 \\
\hline G30A & 0.1 & 0.1 & 134 & 0.0005 \\
\hline G30F & -4.9 & -1.5 & 99 & $<0.0001$ \\
\hline S117V & 5.1 & 2.0 & 133 & 0.05 \\
\hline S117I & 4.2 & 1.7 & 128 & 0.005 \\
\hline S117F & $2.8^{\S}$ & $1.1 \S$ & $132 \S$ & 0.1 \\
\hline N132M & 3.6 & 1.5 & 134 & 0.4 \\
\hline N132F & 3.3 & 1.3 & 134 & 0.4 \\
\hline N132I & 3.0 & 1.2 & 140 & 0.2 \\
\hline S117A/N132I & 5.3 & 2.0 & 121 & 0.2 \\
\hline S117A/N132M & 4.7 & 1.8 & 120 & 0.3 \\
\hline S117I/N132M & 5.5 & 2.0 & 123 & 0.002 \\
\hline S117I/N132I & 3.6 & 1.4 & 117 & 0.003 \\
\hline
\end{tabular}

†Positive values indicate stabilized proteins; negative values indicate destabilization. Numbers are relative to wild type (WT) [melting temperature $\left(T_{\mathrm{m}}\right)=66.48^{\circ} \mathrm{C}$ ], except for the D20 substitutions, E11N, E11H, S117A/N132I, and S117A/N132M, which were made in the pseudo wild-type (WT*) background (6), and were compared to this protein $\left(T_{\mathrm{m}}=65.10^{\circ} \mathrm{C}\right)$. Comparing the WT and $\mathrm{WT}^{*}$ proteins, $\Delta G_{\mathrm{WT}^{*}}-\Delta G_{\mathrm{WT}}$ at $68.4^{\circ} \mathrm{C}$ is $-0.53 \mathrm{kcal} \cdot \mathrm{mol}^{-1}$. Reversibilities improved as scan rate increased from 1 to $4^{\circ} \mathrm{C} \cdot \mathrm{min}^{-1}$ for all proteins except E11F, where obvious precipitation resulted after thermal melting. Proteins for which reversibility did not exceed $75 \%$ were E11M and G30F. The substitution S117A has been measured to have a $\Delta \Delta G$ of $1.3 \mathrm{kcal} \cdot \mathrm{mol}^{-1}(7)$, and that for N132A was inferred to be $0.3 \mathrm{kcal} \cdot \mathrm{mol}^{-1}(8)$, although it has not been determined directly.

$¥$ Activities of the mutant proteins were compared with the WT or $\mathrm{WT}^{*}$ rate by dividing the initial reaction rate of the mutant lysozyme by the initial rate of WT or WT* to get relative rates. The initial rate of the WT enzyme was $13 \mu \mathrm{mol} \cdot \mathrm{min}^{-1} \cdot \mathrm{mg}^{-1} \cdot \mathrm{ml}^{-1}$ of 1 -acetylglucosamine equivalents (9).

§From ref. 10.

Mutations were made in either the WT or the WT* T4 lysozyme (6) sequence. Mutant T4 lysozyme sequences were subcloned and expressed in plasmid expression vector pHN1403 (14). Escherichia coli strain RR1 was transformed with the subcloned plasmid mixtures, and ampicillin-resistant transformants were isolated. Clones bearing the mutant T4

Abbreviations: WT, wild type; $\mathrm{WT}^{*}$, pseudo-wild type; $T_{\mathrm{m}}$, melting temperature.

tPresent address: Kirin Brewing Company, Ltd., Central Laboratories for Key Technology, 1-13-5, Fukura, Kanazawa-ku, Yokohama, 236, Japan.

†To whom reprint requests should be addressed. 


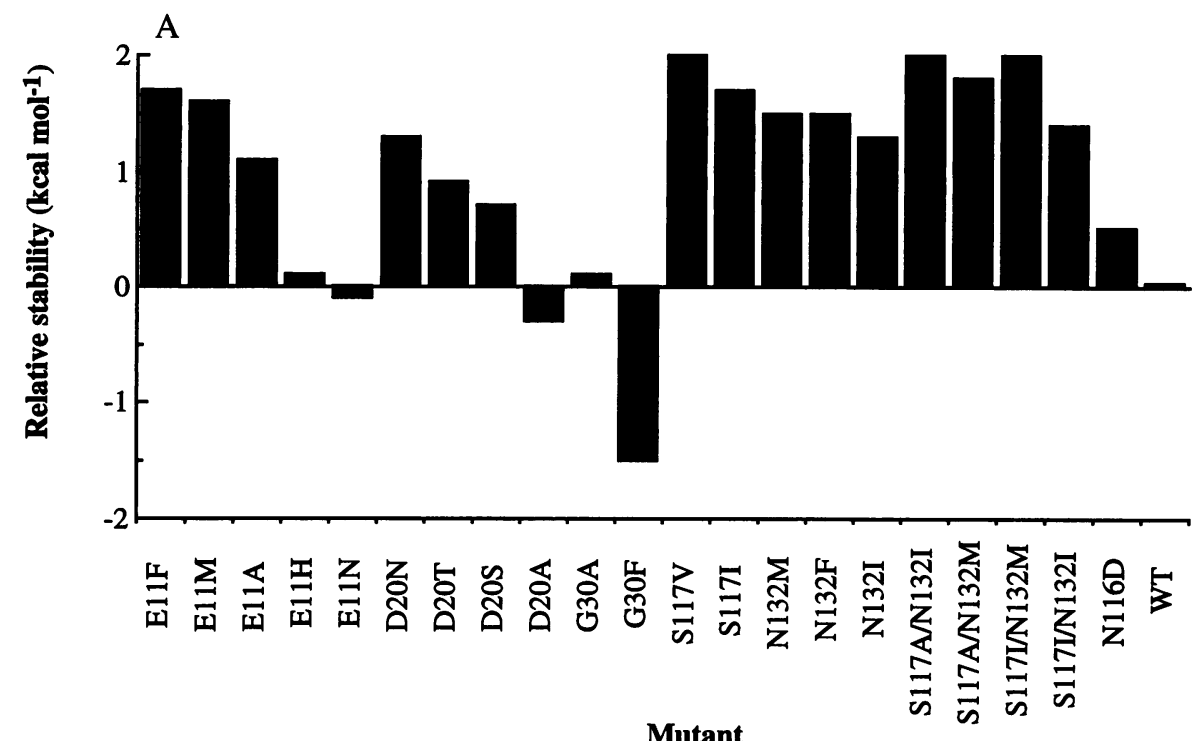

Mutant

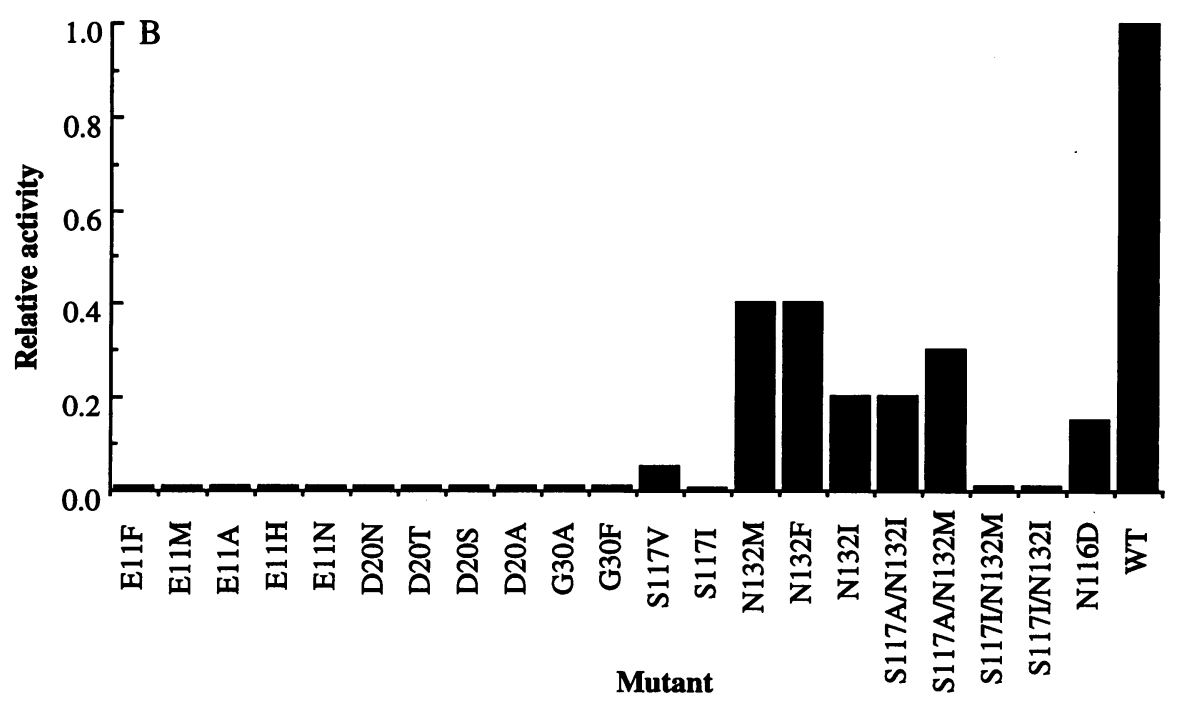

FIG. 1. Comparison of the stability and activity of mutant lysozymes; data from Table 1. $(A)$ Stability relative to the native protein (positive values indicate variants more stable than WT). $(B)$ Activity relative to the native protein.

lysozyme genes were identified, grown in liquid culture, and stored in glycerol at $-80^{\circ} \mathrm{C}(14)$. Mutant protein was produced from fermentation broths grown from these glycerol stocks and column-purified as described (14).

Stability Measurements. Two-state van't Hoff thermodynamic parameters were determined from circular dichroism (CD)-monitored thermal melts of T4 lysozyme mutants in 0.10 $\mathrm{M}$ sodium chloride/ $0.086 \mathrm{M}$ sodium acetate $/ 0.014 \mathrm{M}$ acetic acid, $\mathrm{pH} 5.42(15)$. The enthalpy of unfolding $(\Delta H)$ was determined at the $T_{\mathrm{m}}$ of the mutant proteins. $T_{\mathrm{m}}$ and $\Delta H$ at $T_{\mathrm{m}}$ were not functions of scan rate for any mutant, but both are approximations in the case of mutant E11F where precipitation occurred upon unfolding (Table 1).

Isothermal differences in free energies of unfolding, $\Delta \Delta G$, were calculated from $T_{\mathrm{m}}$ and $\Delta H$ at $T_{\mathrm{m}}$, using a constant $\Delta C_{\mathrm{p}}$ model at $68.4^{\circ} \mathrm{C}$, the average value of $T_{\mathrm{m}}$ for all proteins with $>75 \%$ reversibility. The value of $\Delta C_{\mathrm{p}}$ was taken as 3.5 $\mathrm{kcal} \cdot \mathrm{mol}^{-1} \cdot \mathrm{deg}^{-1}$. Variation of $\Delta C_{\mathrm{p}}$ from 1.5 to $5.5 \mathrm{kcal} \cdot$ $\mathrm{mol}^{-1} \cdot \mathrm{deg}^{-1}$ shifted the mean absolute value of the mutant $\Delta \Delta G$ values by $\pm 20 \mathrm{cal}^{\circ} \mathrm{mol}^{-1}$ with the worst case being mutant $\mathrm{G} 30 \mathrm{~F}$, which has both a $T_{\mathrm{m}}$ well away from the isotherm as well as a slightly lowered $\Delta H\left(T_{\mathrm{m}}\right)$. Random error estimates for $\Delta \Delta G$ are $\pm 0.1 \mathrm{kcal} \cdot \mathrm{mol}^{-1}$ for mutants with stabilities close to WT and WT* but increased with $T_{\mathrm{m}}$ due to the shortened posttransition baselines. For the highest $T_{\mathrm{m}}$ value we estimate the random error in $\Delta \Delta G$ to be $\pm 0.3 \mathrm{kcal} \cdot \mathrm{mol}^{-1}$. All $T_{\mathrm{m}}$ and $\Delta H$ values are averages of at least four independent thermal denaturations.

Activity Measurements. Enzymatic activity was measured by monitoring the production of reducing sugars, over time, as the mutant lysozymes digested $E$. coli cell walls (9). Assays were run in $50 \mathrm{mM}$ sodium phosphate, $\mathrm{pH} 7.6$ at $22^{\circ} \mathrm{C}$. Cell walls for the assay were prepared according to Becktel and Baase (16), but the trypsin treatment of the washed cell walls was omitted. The cells were used at an $\mathrm{OD}_{600}$ of 0.4 . Enzyme concentrations were adjusted to allow the rates to be measured over a similar time course. The dynamic range of the assay was $1.4 \mathrm{OD}_{690}$ units.

Crystallography. Protein crystals were obtained by vapor diffusion using a "hanging-drop" method (17). X-ray diffraction data were collected using a Xuong-Hamlin multiwire detector. Structures were refined with the program TNT (18) (see Figs. 2 and 3), and crystallographic models were built with O (19).

\section{RESULTS}

The catalytic residues $(9,11,12)$ Glu-11 and Asp-20 were changed to obtain the following mutant lysozymes: E11N, 
E11H, E11A, E11M, and E11F; D20A, D20S, D20T, and D20N. Of these nine mutant lysozymes, eight had no measurable enzymatic activity and the ninth, D20A, was reduced 2000 -fold (Table 1). Six of the proteins were stabilized against thermal denaturation by $0.7-1.7 \mathrm{kcal} \cdot \mathrm{mol}^{-1}$ relative to the WT

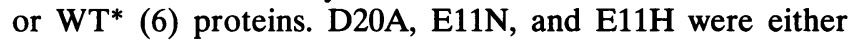
slightly destabilized or unaffected by the mutation.

Ser-117 and Asn-132, which interact with the peptide part of the cell-wall substrate (11), were also mutated, as was Gly-30, which contributes to saccharide binding $(11,12)$. Relative to WT, S117I and S117V were stabilized by 1.7 and 2.0 $\mathrm{kcal} \cdot \mathrm{mol}^{-1}$, respectively, whereas enzymatic activity was reduced by 200 - and 24-fold. Proteins N132M, N132I, and N132F were stabilized by $1.2-1.5 \mathrm{kcal} \cdot \mathrm{mol}^{-1}$, but activity was reduced 2.5- to 5-fold (Table 1). G30A was slightly stabilized, whereas G30F was destabilized by $1.5 \mathrm{kcal} \cdot \mathrm{mol}^{-1}$; both substitutions substantially reduced enzymatic activity.

X-ray crystal structures of the stabilized lysozymes D20N, D20S, E11M, and E11A were determined (Figs. 2 and 3), as were those for the destabilized lysozymes D20A and E11N and E11H. Like the native Asp-20, the side-chain oxygens of Ser-20 and Asn-20 hydrogen-bond to main-chain nitrogens of residues 22 and 24. No such interactions are apparent in mutant D20A, consistent with its lower stability. These substitutions caused little change overall in the protein structure.

The changes in the structures of the stabilized lysozymes E11M and E11A were more dramatic (Fig. 3). Both substitutions led to an overall "hinge-bending" motion of the protein. The $\mathrm{N}$ - and $\mathrm{C}$-terminal domains were rotated toward each other, by $3.7^{\circ}$ for mutant E11M and $3.4^{\circ}$ for E11A, partially closing the active site. This global motion resembles that seen in the structure of the complex between product and enzyme (11), where the rotation was $5.1^{\circ}$. Mutant lysozymes E11N and E11H are approximately stability-neutral and exhibit no hingebending motion.

\section{DISCUSSION}

We began with the hypothesis that residues in a protein that participate in catalysis are not optimized for stability. If this were true, it should be possible to substitute for such residues, reducing the activity of the protein but concomitantly increasing its stability. The present results are consistent with this hypothesis. At the five sites tested, substitutions were identified that decreased the activity but increased the stability of T4 lysozyme (Table 1 and Fig. 1). Strikingly, many of these substitutions stabilize T4 lysozyme more than previously characterized point mutations (5). The only known point mutation that stabilizes the protein in this range is Ser-117 $\rightarrow$ Phe (10) $\left(\Delta \Delta G=1.1 \mathrm{kcal} \cdot \mathrm{mol}^{-1}\right.$, Table 1$)$, but this site is now known to be in the substrate-binding region (11), consistent with the stability-function hypothesis. Not all substitutions at the sites tested stabilize the protein. This result is not inconsistent with the stability-function hypothesis because not every substitution at a given site is predicted to be stabilizing; this is a point to which we shall return. We also note that there are additional residues that contact the substrate (11) that remain to be tested.

For those mutants that are stabilized, the increase in stability appears to have a similar origin: the native protein is preorganized to complement the ligand or the transition state, whereas the substituted residues complement their local protein environment. Because this local environment is the substrate-binding site, the increased stability of the mutants comes at the expense of catalytic activity. The improved complementarity of the substituted residues for their local environment can arise from improved electrostatic, van der Waals, or hydrophobic interactions or through a reduction of strain present in the native protein [Warshel and coworkers (4) have described a theoretical basis for the relationship between stability and the electrostatic component of preorganization in active sites].

Glu-11 is thought to act catalytically as a proton donor (11, 12). Consistent with this role, its $\mathrm{pK}_{\mathrm{a}}$ in folded lysozyme is 1.2 units higher than that of an unperturbed glutamate (20). This $\mathrm{pK}_{\mathrm{a}}$ perturbation may be thought of as "strain" energy; it is a cost of catalysis that the native protein pays on folding but that the mutants do not pay because they are uncharged [mutants E11A, E11M, and E11F are $1.2-1.3 \mathrm{kcal} \cdot \mathrm{mol}^{-1}$ more stabilized relative to $\mathrm{WT}$ at $\mathrm{pH} 5.4$ than they are at $\mathrm{pH} 3.01$ (data not shown). At the lower $\mathrm{pH}$ the $\mathrm{pK}_{\mathrm{a}}$ perturbation cost should be small]; the reduction or elimination of electrostatic "strain" in

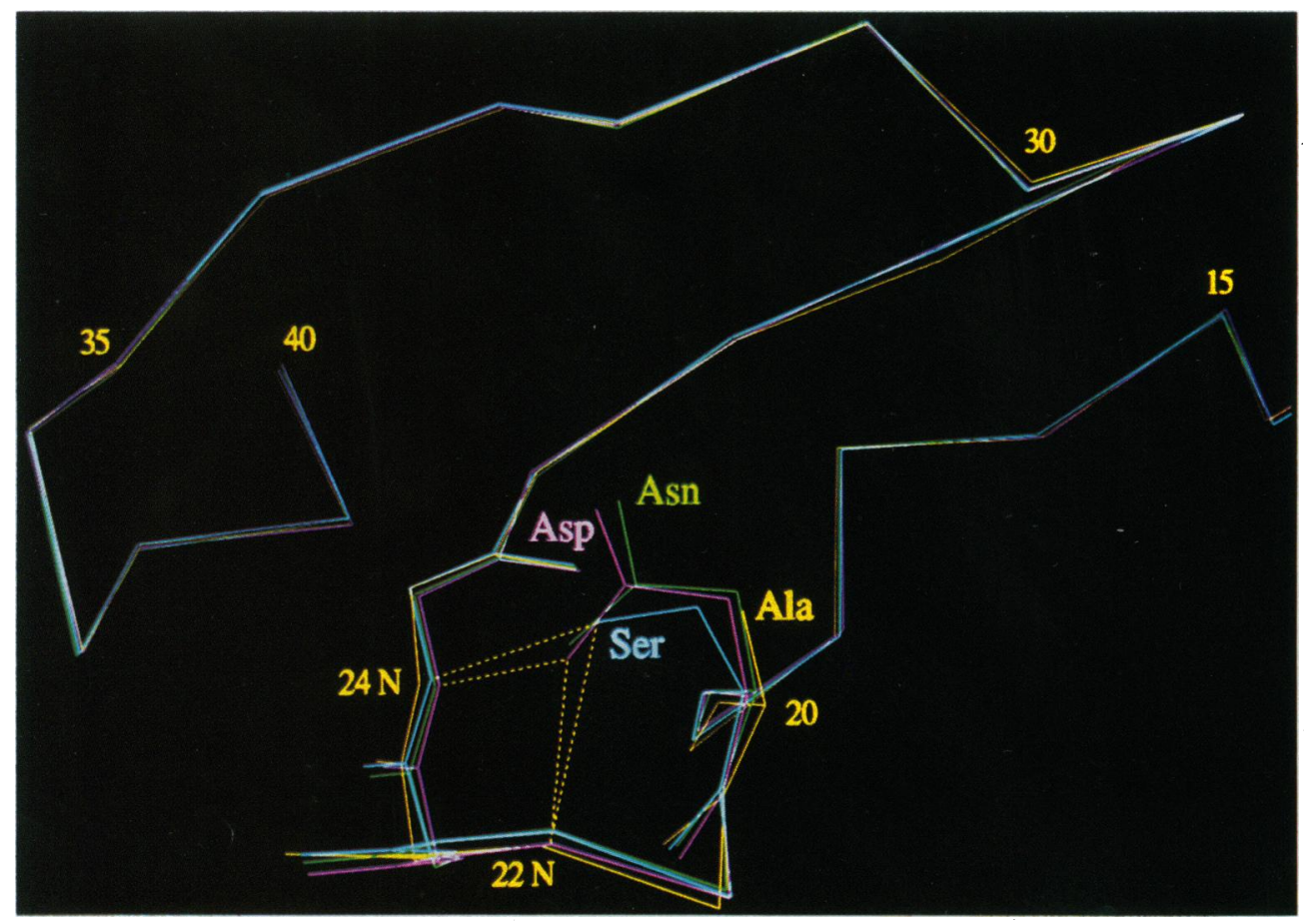

FIG. 2. Superposition of the structures of mutant D20A (yellow) mutant D20S (cyan), mutant D20N (green), and $\mathrm{WT}^{*}$ (magenta), in the region of residue 20 . The $\mathrm{C}^{\alpha}$ carbons are shown except for positions 2224 , where the main-chain atoms are shown, and position 20 , where the full residues are shown. Hydrogen bonds between the main-chain nitrogens of residues 22 and 24 and side-chain oxygens of the Ser-20 and Asp-20 are explicitly drawn (yellow dashed lines). For WT* and mutant D20N structures, the hydrogenbond distances were 2.7-2.9 $\AA$. For ihe mutant D20S structure, the hydrogen-bond distances are 3.2 and $3.3 \AA$. The crystallographic statistics for the three structures are as follows: resolution, 1.85-2.0 $\AA ̊$; data completeness, $88-90 \%$; agreement between equivalent intensity measurements, $R_{\text {merge }}, 3.1-$ $4.5 \%$; crystallographic $R$ factor, 16.2-16.9\%; rms discrepancies in bond lengths $0.015-0.016 \AA$ and in bond angles $2.6-2.8^{\circ}$ relative to ideal values. 


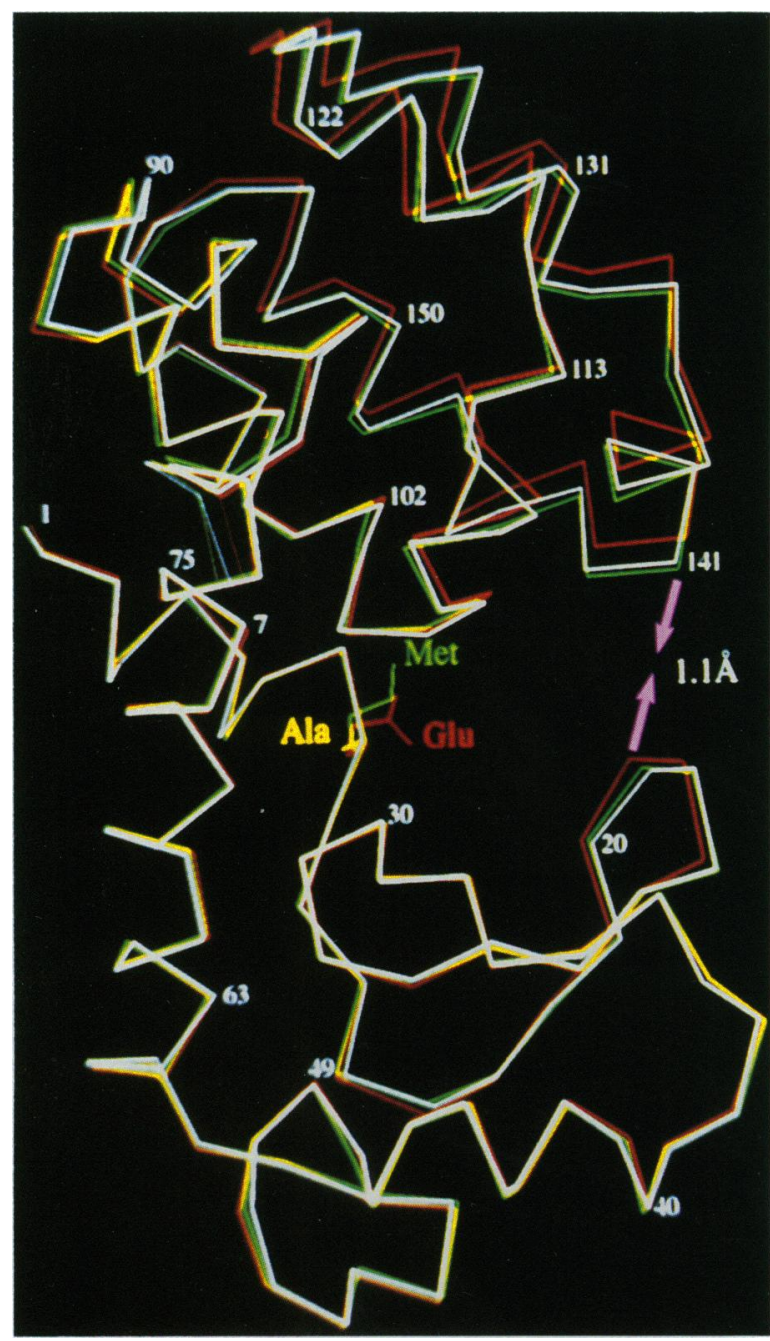

FIG. 3. Superposition of the structures of mutant E11M (green), mutant E11A (white), and WT (red). The structures have been overlaid by using their $\mathrm{N}$-terminal domains (residues 1-59). The C-terminal domains (residues 80-160) of mutants E11M and E11A closely overlap, but because of the domain "hinge-bending", they are displaced relative to the C-terminal domain of the WT protein (rms deviation to WT, 0.80 and $0.73 \AA$; rms deviation to each other, 0.36 $\AA)$. The $C^{\alpha}$ atoms of Gln-141 and Thr-21, which help define the entrance to the active site, have moved together by $1.1 \AA$ in mutant E11M compared with WT (magenta arrows). Data completeness was 92\% to 2.5 - $\AA$ resolution for mutant E11M and $94 \%$ to 2.8 - $\AA$ resolution for mutant E11A. The crystallographic statistics were as follows: $R_{\text {merge }}, 5.9 \%$ and $7.4 \% ; R$ factor of $16.7 \%$ and $14.5 \%$; rms bond lengths of 0.018 and $0.016 \AA$ and $\mathrm{rms}$ angles of $2.5^{\circ}$ and $2.4 \%$, relative to ideal values.

the mutant proteins (at $\mathrm{pH} 5.4$ ) contributes to their increased stability compared with native lysozyme. This reduction of electrostatic "strain" also inactivates them: the mutant proteins have no proton to donate to the substrate. Hydrophobicity also seems to contribute to stability at this site; substitutions that take advantage of opportunities for burying nonpolar surface area are more stable than those that do not. Thus $\mathrm{E} 11 \mathrm{~F}$ and E11M are more stable than E11A, and all three are more stable than $\mathrm{E} 11 \mathrm{H}$ or $\mathrm{E} 11 \mathrm{~N}$. This observation is consistent with the crystal structure of E11M, where Met-11 packs against a nonpolar surface in the active site. $\mathrm{E} 11 \mathrm{H}$ and $\mathrm{E} 11 \mathrm{~N}$, which are approximately stability-neutral, presumably gain energy through removal of the carboxylate function but lose energy because they introduce polar atoms in place of the methylene part of the glutamate side chain. Their difference in shape relative to the glutamate could also result in unfavorable steric interactions.

Changes in the polarity of the side chain at site 11 seem to be associated with a global change in structure. Mutants with alanine or methionine undergo a hinge-bending motion that partly "closes down" the active site. Mutants with asparagine or histidine, as well as the wild-type glutamate, do not display this conformational change. It may be the reduction in polar surface area at position 11 that allows the $\mathrm{N}$ - and C-terminal domains to partly close down upon each other. In a complex of lysozyme with peptidoglycan (11), which also displays this global motion, the polar surface area of Glu-11 is buried by ligand atoms. These two similar structural accommodations, the one responding to apolar substitutions of a catalytic residue, the other responding to ligand association with this residue, may reflect a similar energy balance and mechanism.

Asp-20 has been proposed to participate in the nucleophilic attack on the substrate (9), although other roles have not been excluded (11). One of the side-chain carboxyl oxygens of Asp-20 forms two hydrogen bonds to main-chain nitrogens that fix its orientation relative to the active site (Fig. 2). The second carboxylate oxygen is partly buried from solvent and is uncompensated by surrounding residues, possibly freeing it to interact with the substrate. Freedom to interact with substrate implies failure to complement its local protein environment. The stabilizing substitutions Asp-20 $\rightarrow$ Asn and Asp-20 $\rightarrow$ Ser, and presumably Asp-20 $\rightarrow$ Thr (Table 1, D20N, D20S, and D20T, respectively; Fig. 1), maintain the main-chain to sidechain hydrogen bonds present in the native protein (Fig. 2) but do not suffer the apparent cost of burying a charged group. Mutant D20A cannot maintain the hydrogen bonds to the main-chain nitrogens present in the native protein (Fig. 2) and is destabilized rather than stabilized. Although the activity of mutant D20A is much diminished compared with native lysozyme, its activity is higher than the stabilized substitutions, which have no detectable activity. Like the substitutions at Glu-11, the stabilizing substitutions at Asp-20 are considerably stabilized relative to the native protein (Table 1 and Fig. 1); they too are inactive.

The role of Ser-117 and Asn-132 in ligand recognition seems to be the formation of hydrogen bonds to the peptide moiety of the substrate and the reaction product (11). In the native structure these residues make a short hydrogen bond $(2.5 \AA)$, possibly causing steric strain $(7,10)$. They also flank and help define the groove that the peptide part of the ligand occupies in the presumed enzyme-substrate complex. Mutations at these sites presumably increase protein stability by relieving the putative strain present in the native structure and by interacting with residues defining the binding-site groove. Both mutants S117A (7) and N132A (8) are stabilized relative to the native protein, consistent with the strain-relief mechanism. Some variants such as mutants S117V and N132M with larger side chains are further stabilized (Table 1). This result suggests that interactions between these side chains and surrounding parts of the substrate-binding cleft can also stabilize mutant lysozymes. By interacting with this groove the substitutions at these residues are competing for the same binding site and binding energy as the substrate; this leads to more stable but less active mutant lysozymes (Table 1, Fig. 1).

We believe that the relationship between protein stability and function is not limited to T4 lysozyme but is a general phenomenon. Results from several other proteins support this view. In citrate synthase, mutations of the substrate-binding residues His-274 and Asp-375 increased enzyme thermal stability by $4-10^{\circ} \mathrm{C}$, concomitantly reducing activity by 3 to 4 orders of magnitude (21). By mutating active-site basic residues to alanine, Meiering et al (22) stabilized barnase by $0.15-0.64 \mathrm{kcal} \cdot \mathrm{mol}^{-1}$, while decreasing activity by $15-99 \%$. In both cases the authors linked enzymatic strain to protein activity. Deletion of an active-site loop in staphylococcal 
nuclease increased protein stability by $2.5 \mathrm{kcal} \cdot \mathrm{mol}^{-1}$ while reducing $V_{\max } 40$-fold (23); mutations at the catalytic residue Glu-43 also increased stability while decreasing activity (24). The active-site mutation Asp-26 $\rightarrow$ Ala in thioredoxin improved stability by $1 \mathrm{kcal} \cdot \mathrm{mol}^{-1}$ and increased $K_{\mathrm{m}} 5$-fold to thioredoxin reductase (25). In retinoic acid-binding protein, active-site mutations Arg-111 $\rightarrow$ Gln and Arg-131 $\rightarrow$ Gln (26) decreased ligand binding while improving stability by 3.0 and $3.7 \mathrm{kcal} \cdot \mathrm{mol}^{-1}$. Similar results have been reported for several other proteins (27-29, 39). In $\lambda$ cro repressor (30), stability has been significantly improved by substitutions to DNA-binding residues at the cost of reduced operator affinity. These residues occur in convex regions of the protein's surface, suggesting that the interplay between stability and function is not limited to the concave environments typical of enzyme active sites. The finding that most main-chain conformational strain occurs in the functional regions of proteins (31) and the view of enzymes as having an "entatic state" (32) are also consistent with the hypothesis.

Having begun by stating the stability-function hypothesis in an admittedly strong and provocative form, we must now consider some of its limitations. The hypothesis is not intended to suggest that every substitution of a functional residue will improve stability-some residues may complement the site better, whereas others may complement the site worse than the native residue. An appropriate analogy is that of ligand binding to an active site. A given active site may bind some molecules while other molecules will not bind at all. The hypothesis does not address the degree to which a particular protein is optimized for function or stability. It might be possible to improve the stability and the activity of a protein with the same substitution (in practice, single substitutions that improve the activity of a protein have been rare). In general, the ability to stabilize a protein by mutating functional residues is constrained by the available substitutions. If one is restricted to the 20 naturally occurring amino acids as substitutions, and given the virtually unlimited chemistry available to ligands, the hypothesis does not predict that it will always be possible to improve stability.

We have argued that it is possible to stabilize proteins by sacrificing their activity. Some may find this perverse. We briefly sketch three possible applications. $(i)$ Thermostable proteins from thermophilic bacteria are often less active at low temperatures than their mesophilic counterparts $(33,34)$ which, in turn, seem less active than their psychrophilic counterparts (35). Higher temperature restores the activity of the thermostable proteins. It may prove possible to stabilize proteins through binding-site mutations while retaining sufficient activity for the proteins to be useful at higher temperatures. Multi-binding-site proteins could be stabilized by attenuating a function at one site or by sacrificing specificity. (ii) Engineering a novel binding site or new functionality is expected to destabilize a protein (36-38). Creating such sites or functions may require stabilizing the protein in other regions, possibly at the cost of the protein's normal function. (iii) A logical inversion of the stability-function hypothesis suggests that it should be possible to test putative ligandbinding sites by looking for stabilizing substitutions at such sites.

The compensation between stability and functional requirements may contribute to two striking features of proteinstheir large size and low stability.

We thank S. Snow, J. Wozniak, and J. Lindstrom for expert technical assistance and E. Baldwin, A. Morton, and D. Barrick for insightful discussions. B.K.S. is supported by the Cancer Research Fund of the Damon Runyon-Walter Winchell Foundation Fellowship, DRG-1228. R.K. was supported by the Kirin Brewery Company. This work was supported in part by a grant to B.W.M. from the National Institutes of Health (GM21967).

1. Pauling, L., Campbell, D. H. \& Pressman, D. (1943) Physiol. Rev. 23, 203-219.

2. Kauzmann, W. (1959) Adv. Protein Chem. 14, 1-63.

3. Warshel, A. (1978) Proc. Natl. Acad. Sci. USA 75, 5250-5254.

4. Warshel, A., Sussman, F. \& Hwang, J.-K. (1988) J. Mol. Biol. 201, 139-159.

5. Matthews, B. W. (1993) Annu. Rev. Biochem. 62, 139-160.

6. Matsumura, M. \& Matthews, B. W. (1989) Science 243, 792-794.

7. Blaber, M., Baase, W. A. \& Matthews, B. W. (1994) J. Mol. Biol., in press.

8. Zhang, X.-J., Baase, W. A. \& Matthews, B. W. (1992) Protein Sci. 1, 761-776.

9. Hardy, L. W. \& Poteete, A. R. (1991) Biochemistry 30, 94579463.

10. Anderson, D. E., Hurley, J. H., Nicholson, H., Baase, W. A. \& Matthews, B. W. (1993) Protein Sci. 2, 1285-1290.

11. Kuroki, R., Weaver, L. \& Matthews, B. W. (1993) Science 262, 2030-2033.

12. Anderson, W. F., Grutter, M. G., Remington, S. J., Weaver, L. H. \& Matthews, B. W. (1981) J. Mol. Biol. 147, 523-543.

13. Kunkel, T. A., Roberts, J. D. \& Zakour, R. A. (1987) Methods Enzymol. 154, 367-382.

14. Poteete, A. R., Dao-pin, S., Nicholson, H. \& Matthews, B. W. (1991) Biochemistry 30, 1425-1432.

15. Dao-pin, S., Baase, W. A. \& Matthews, B. W. (1990) Proteins 7, 198-204.

16. Becktel, W. J. \& Baase, W. A. (1985) Anal. Biochem. 150, 258-263.

17. Eriksson, A. E., Baase, W. A. \& Matthews, B. W. (1993) J. Mol. Biol. 229, 747-769.

18. Tronrud, D. E. (1992) Acta Crystallogr. Sect. A 48, 912-916.

19. Jones, T. A., Zou, J. Y., Cowan, S. W. \& Kjeldgaard, M. (1991) Acta Crystallogr. Sect. A 47, 110-119.

20. Anderson, D. E., Lu, J., McIntosh, L. P. \& Dahlquist, F. W. (1993) in NMR of Proteins, eds. Clore, G. M. \& Gronenborn, A. M. (CRC, Boca Raton, FL), pp. 258-304.

21. Zhi, W., Srere, P. A. \& Evans, C. T. (1991) Biochemistry 30, 9281-9286.

22. Meiering, E. M., Serrano, L. \& Fersht, A. R. (1992) J. Mol. Biol. 225, 585-589.

23. Poole, L. B., Loveys, D. A., Hale, S. P. \& Gerlt, J. A. (1991) Biochemistry 30, 3621-3627.

24. Hibler, D. W., Stolowich, N. J., Reynolds, M. A. \& Gerlt, J. A. (1987) Biochemistry 26, 6278-6286.

25. Gleason, F. K. (1992) Protein Sci. 1, 609-616.

26. Zhang, J., Liu, Z.-P., Jones, T. A., Gierazch, L. M. \& Sambrook, J. F. (1992) Proteins 13, 87-99.

27. Kanzaki, H., McPhie, P. \& Miles, E. W. (1991) Arch. Biochem. Biophys. 284, 174-180.

28. Kelley, R. F., DeVos, A. M. \& Cleary, S. (1991) Proteins 11, $35-44$.

29. Kimura, S., Nakamura, H., Hashimoto, T., Oobatake, M. \& Kanaya, S. (1992) J. Biol. Chem. 267, 21535-21542.

30. Pakula, A. A. \& Sauer, R. T. (1989) Proteins 5, 202-210.

31. Herzberg, O. \& Moult, J. (1991) Proteins 11, 223-229.

32. Williams, R. J. (1972) Cold Spring Harbor Symp. Quant. Biol. 36, 53-62.

33. Mozhaev, V. V., Berezin, I. V. \& Martinek, K. (1988) CRC Crit. Rev. Biochem. 23, 235-281.

34. Varley, P. G. \& Pain, R. H. (1991) J. Mol. Biol. 220, 531-538.

35. Bjarnason, J. B., Asgeirsson, B. \& Fox, J. W. (1993) in Biocatalyst Design for Stability and Specificity, eds. Himmel, M. E. \& Georgiou, G. (Am. Chem. Soc., Washington, DC), pp. 68-82.

36. Eriksson, A. E., Baase, W. A., Wozniak, J. A. \& Matthews, B. W. (1992) Nature (London) 355, 371-373.

37. Braxton, S. \& Wells, J. A. (1992) Biochemistry 31, 7796-7801.

38. Scrutton, N. S., Deonarain, M. P., Berry, A. \& Perham, R. N. (1992) Science 258, 1140-1142.

39. Inoue, M., Yamada, H., Hashimoto, Y., Yasukochi, T., Hamaguchi, K., Miki, T., Horiuchi, T. \& Imoto, T. (1992) Biochemistry 31, 8816-8821. 